\title{
Comment on: "Current Status and Trends in Performance-Based Risk-Sharing Arrangements Between Healthcare Payers and Medical Product Manufacturers"
}

\author{
Alessandro Curto • Livio Garattini
}

Published online: 16 August 2014

(C) Springer International Publishing Switzerland 2014

Dear Editor,

We read with interest the article "Current Status and Trends in Performance-Based Risk-Sharing Arrangements Between Healthcare Payers and Medical Product Manufacturers" [1] published recently in your journal.

The authors refer for their review to a particular taxonomy described in a previous publication of theirs [2], which should imply four categories: (i) coverage with evidence development (CED); (ii) performance-linked reimbursement (PLR), (iii) conditional treatment continuation (CTC), and (iv) financial/utilization arrangements (FU). Because we found the distinction between the first three categories somewhat unclear, we looked at their earlier publication and found three categories (PLR, CED, CTC), not four. This article also reported that a good example of CTC was Alzheimer medications in Italy, a multi-product scheme launched very early in 2001, which is not listed as a management entry agreement by AIFA, the Italian Medicines Agency. Then we analyzed the guidelines prepared by the International Society For Pharmacoeconomics and Outcomes Research [3], coauthored by one of the authors, and CTC was classified under PLR, together with "outcomes and money back guarantees" as further sub-classification.
Because the taxonomy used in the article does not fully coincide with that in the referenced documents, we would like the authors to provide further explanation. We would be interested in understanding how the authors classified the arrangements in the UK (29) and Italy (36), which are the two leading countries in this field according to the article.

Disclosures The authors have no conflicts of interest to declare and no funding was received for the preparation of this letter.

\section{References}

1. Carlson JJ, Gries KS, Yeung K, Sullivan SD, Garrison LP Jr. Current status and trends in performance-based risk-sharing arrangements between healthcare payers and medical product manufacturers. Appl Health Econ Health Policy. 2014;12:231-8.

2. Carlson JJ, Sullivan SD, Garrison LP, Neumann PJ, Veenstra DL. Linking payment to health outcomes: a taxonomy and examination of performance-based reimbursement schemes between healthcare payers and manufacturers. Health Policy. 2010;96(3):179-90. doi:10.1016/j.healthpol.2010.02.005.

3. Garrison LP, Towse A, Briggs A, De Pouvourville G, Grueger J, Mohr, Severens H, Siviero P, Sleeper M. Performance-based risksharing arrangements-good practices for design, implementation, and evaluation: report of the ISPOR good practices for performance-based risk-sharing arrangements task force. Value Health. 2013;16(5):703-19.
A. Curto $\cdot$ L. Garattini $(\bowtie)$

CESAV, Center for Health Economics, IRCCS Institute for

Pharmacological Research 'Mario Negri', Via Camozzi 3,

24020 Ranica, Italy

e-mail: lgarattini@marionegri.it 